14

\title{
Рентгеновские компьютерные методы исследований структурной целостности семян и их значение в современном семеноведении
}

\author{
() М.В. Архипов,,$^{1,3}$ Н.С. Прияткин, ${ }^{1,}$ Л.П. Гусакова, ${ }^{1}$ Н.Н. Потрахов, ${ }^{2}$ А.Ю. Грязнов, ${ }^{2}$ В.Б. Бессонов, ${ }^{2}$ \\ А.В. Ободовский, ${ }^{2}$ Н.Е. Староверов ${ }^{2}$ \\ ${ }^{1}$ Агрофизический научно-исследовательский институт, \\ 195220 Санкт-Петербург, Россия \\ ${ }^{2}$ Санкт-Петербургский государственный электротехнический университет „ЛЭТИ“ им. В.И. Ульянова (Ленина), \\ 197376 Санкт-Петербург, Россия \\ ${ }^{3}$ Северо-Западный центр междисциплинарных исследований проблем продовольственного обеспечения, \\ 196608 Пушкин, Санкт-Петербург, Россия \\ I e-mail: prini@mail.ru
}

\section{(Поступило в Редакцию 29 апреля 2018 г.)}

Рассмотрены рентгеновские компьютерные методы исследования, - проекционная микрофокусная рентгенография и микрофокусная рентгеновская компьютерная томография, — применяемые для изучения проблемы скрытой дефектности семян и исследования ее влияния на посевные качества. Приведены описание и основные характеристики технических средств, используемых для получения цифровых двумерных и трехмерных (томографических) рентгеновских изображений семян, обсуждаются возможные способы применения их количественной ЭВМ-программной обработки и анализа. Сформулированы выводы о возможностях методов проекционной микрофокусной рентгенографии и микрофокусной рентгеновской компьютерной томографии для изучения особенностей внутренних структур семени, связанных с нарушением его целостности.

DOI: $10.21883 / J T F .2019 .04 .47324 .170-18$

\section{Введение}

Семена как биологические объекты являются сложными многокомпонентными, многопараметрическими нелинейными системами, а в физике для описания таких объектов отсутствует понятийный аппарат. Поэтому при изучении факторов, влияющих на формирование и жизнеспособность семян, имеет смысл рассматривать, прежде всего, их интегральные характеристики как самостоятельного целостного растительного организма и лишь в дальнейшем переходить к исследованию отдельных компонентов, обеспечивающих функционирование системы в целом.

При переходе от организменного уровня оценки к популяционному важное значение приобретает гетерогенность семян, поскольку она приводит к неоднородности будущих организмов, которые, в свою очередь, дадут разнокачественные семена [1]

Современный уровень научных исследований в семеноведении требует применения инструментальных физических методов, позволяющих получить детальную информацию как о внешних, так и внутренних характеристиках структурной целостности семени. На сегодняшний день рентгенография является единственным стандартизованным инструментальным методом, применяемым для решения данной задачи [2-5]. Метод позволяет проводить прижизненные исследования растительных объектов, в том числе семян, не нарушая их структуры и не снижая их жизнеспособности [6]. Анализ публикаций последних лет показывает устой- чивую мировую тенденцию к переходу от визуальной оценки цифровых рентгеновских изображений семян к автоматическому анализу с получением количественных характеристик исследуемых объектов [7-10].

Исследования анатомического строения семян с использованием „виртуальной гистологии“ на основе метода компьютерной фазово-контрастной микротомографии [11], позволяющего оценивать структурные изменения семян не только на организменном, но и на органнотканевом уровне [12]. Основным преимуществом микрофокусной рентгеновской компьютерной томографии (в зарубежной литературе - микротомографии) по сравнению с методом проекционной микрофокусной рентгенографии является гарантированная визуализация скрытых дефектов в области зародыша у семян округлой формы и сравнительно большой толщины, например, сои, кукурузы и др. [13]. Использование метода компьютерной микротомографии в сочетании с количественной программной обработкой $3 D$-изображений, позволяющих рассчитать в том числе процент площади, объемную долю и пористость различных структур и органов семени $[14,15]$, в перспективе может служить эффективным дополнительным инструментом для определения физиологической зрелости и жизнеспособности семян.

Основная задача настоящей работы включает в себя рассмотрение следующих вопросов:

- физико-технические основы методов, используемых для получения цифровых рентгеновских и компьютерных микротомографических изображений семян; 
- характеристики современных аппаратных решений, используемых для получения цифровых рентгеновских и компьютерных микротомографических изображений семян;

- обсуждение основных способов визуализации и анализа цифровых рентгеновских и компьютерных микротомографических изображений семян;

- оценка энергии прорастания, всхожести и компьютерная морфометрия проростков как интегральных показателей для оценки биологической полноценности семян;

- сравнительная оценка возможностей методов цифровой микрофокусной рентгенографии и компьютерной микротомографии для изучения особенностей внутренних структур семени, связанных с нарушением его целостности.

\section{1. Основная часть}

\section{1. Физико-технические основы методов, используемых для получения цифровых рентгеновских и компьютерных микротомографических изображений семян}

Размеры отдельного семени большинства овощных культур и тем более отдельных деталей его структуры составляют от нескольких сотых долей миллиметра до нескольких миллиметров. В связи с этим широко известный в медицинской диагностике контактный способ получения рентгеновских изображений [16] не позволяет в настоящее время обеспечить качество изображения семян, достаточное для обнаружения основных дефектов их внутреннего строения. Для решения этой задачи может быть использован так называемый микрофокусный способ получения рентгеновских изображений [17].

1.1.1. Контактный способ съемки. При съемке контактным способом (рис. 1) используется источник рентгеновского излучения 1 с протяженным фокусным пятном $d_{1}$, эффективный размер которого составляет около $1 \mathrm{~mm}$.

Объект съемки 2 располагается на достаточно большом расстоянии $f$ от источника излучения 1 и вплотную („контактно“) к приемнику изображения 3. Из рисунка видно, что в условиях стандартной - контактной рентгенографии размер фокусного пятна $d$, а также расстояние между источником излучения и объектом $f$ существенно влияют на качество (нерезкость $H_{r}$ ) изображения. При этом расстояние $f$ выбирается, исходя из требований к нерезкости получаемых снимков, с учетом конкретных размеров фокусного пятна рентгеновской трубки $d_{1}$ и толщины объекта. Уменьшение расстояния $f$ (фокусного расстояния) приводит к ухудшению качества снимка вследствие увеличения $H_{r}$. Также даже незначительное удаление приемника изображения от объекта

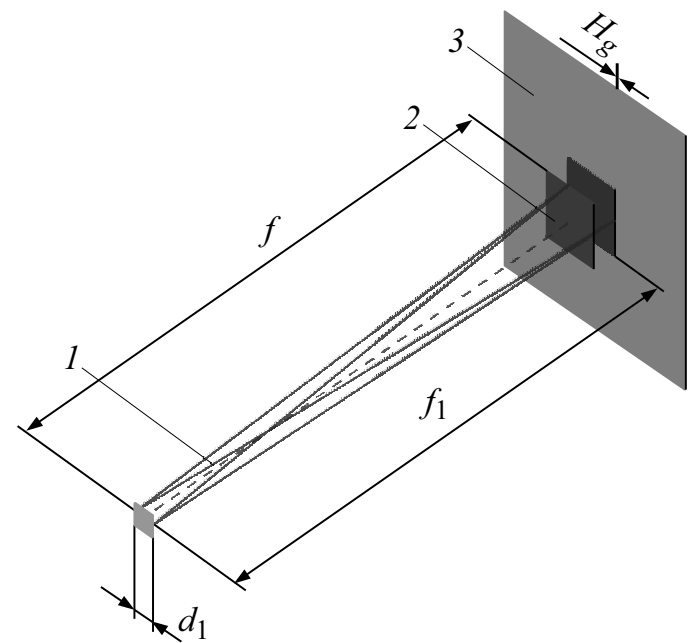

Рис. 1. Рентгенооптическая схема съемки в стандартной рентгенографии - контактный способ.

съемки: уменьшение $f_{1}$ при неизменном $f$ - приводит к значительному ухудшению качества снимка вследствие увеличения $H_{r}$. Очевидно, что для уменышения нерезкости изображения необходимо увеличивать расстояние между объектом и источником излучения. В общем случае отношение расстояний $f$ и $f_{1}$ определяет коэффициент увеличения изображения объекта $m$ по сравнению с его истинными геометрическими размерами

$$
m=f / f_{1}
$$

Соответственно при контактной съемке $f \approx f_{1}$ и $m \approx 1$.

1.1.2. Способ рентгеновской съемки с увеличением изображения. При съемке с увеличением изображения используется источник излучения 1 с так называемым точечным фокусным пятном $d_{2}$ (рис. 2). Практика рентгенографии показывает, что для большинства рентгенодиагностических задач коэффициент увеличения изображения не превышает 5-7 раз [18]. В этом случае для получения резких увеличенных изображений биологических тканей размер фокусного пятна должен составлять менее $0.1 \mathrm{~mm}$ (или $100 \mu \mathrm{m}$ ). Соответственно методика съемки биологических объектов с помощью таких источников излучения в соответствии с ГОСТ 22091.9-86 получила название „микрофокусная рентгенография“, а способ съемки с увеличением изображения - „микрофокусный способ“.

В этом случае объект съемки располагается на определенном расстоянии как от источника излучения 1 , так и от приемника изображения 3. Независимо от того, в каком положении находится объект съемки в пространстве между фокусным пятном источника излучения и плоскостью приемника, резкость полученного изображения в указанном диапазоне значений коэффициента его увеличения сохраняется $-H_{r} \rightarrow 0$. 


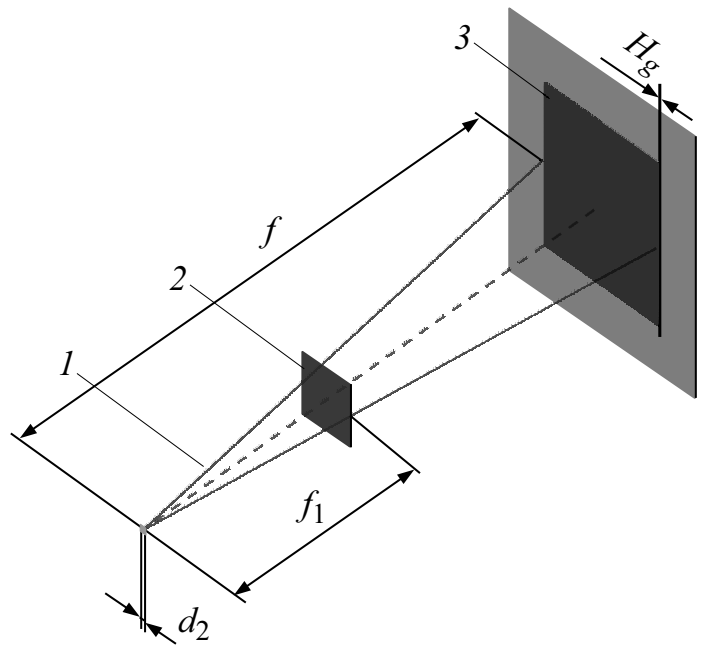

Рис. 2. Рентгенооптическая схема съемки - способ с увеличением изображения.

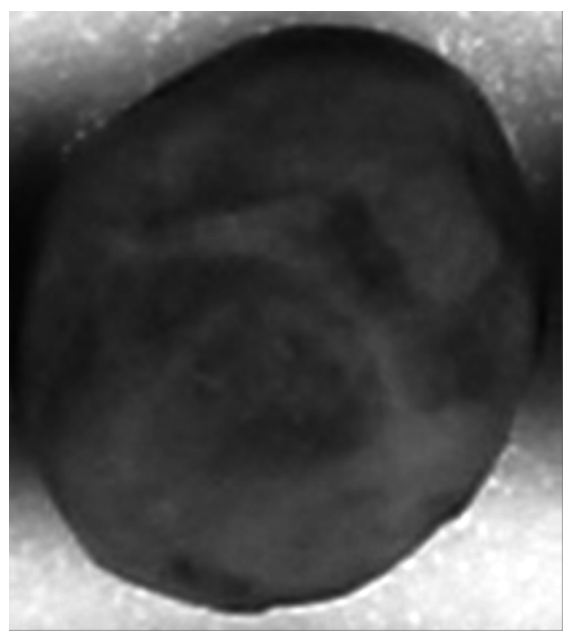

Рис. 3. Увеличенное оптическое изображение тест-объекта (семя гороха).

Для демонстрации преимуществ микрофокусной рентгенографии по сравнению со стандартной рентгенографией в качестве тест-объекта было использовано семя гороха, содержащее структурные элементы размером от нескольких десятков микрометров (рис. 3).

Рентгеновские снимки тест-объекта, полученные по методике стандартной рентгенографии на аппарате с протяженным фокусным пятном без увеличения (контактно) и увеличением изображения, представлены на рис. 4.

Из рисунка видно, что при удалении тест-объекта от приемника изображения (с ростом коэффициента увеличения изображения) информативность получаемых снимков существенно уменьшается по сравнению с контактным снимком вследствие возникающей нерезкости изображения. На рис. 5 представлены рентгеновские снимки того же тест-объекта, полученные по методике микрофокусной рентгенографии на аппарате с точечным фокусным пятном также без увеличения изображения контактно и с увеличением изображения $m$.

На микрофокусных снимках с увеличением изображения по аналогии с оптической микроскопией не только сохраняется резкость изображения, но и по мере роста коэффициента его увеличения обнаруживаются новые детали строения объекта, ранее не различимые на контактном снимке.

Описанные отличительные особенности способа сьемки с увеличением изображения в микрофокусной рентгенографии от контактного способа в стандартной рентгенографии получили название „эффект увеличения глубины резкости“ [19]. Преимущества микрофокусного способа рентгеновской съемки семян по сравнению со стандартным - контактным способом дополнительно проиллюстрированы рентгеновскими изображениями карточки семян артишока (рис. 6) [20].

Поскольку геометрические размеры семян артишока составляют несколько миллиметров, с целью дальнейшего анализа исходное рентгеновское изображение каждого семени, полученное контактным способом съемки на аппарате с протяженным фокусным пятном, рассматривается, например, с помощью лупы или микроскопа. На рис. $6, b$ представлены оптически увеличенные рентгеновские изображения семян. Для сравнения на рис. $6, c$ представлены увеличенные рентгеновские изображения этих же семян, полученные микрофокусным способом съемки.

Чтобы подчеркнуть принципиальное отличие механизмов увеличения рентгеновского изображения объекта исследования: оптическое или электронное (с помощью компьютера) в контактном способе и геометрическое в микрофокусном способе, последний принято также называть способом съемки „с прямым рентгеновским увеличением“ ${ }^{6}[18]$.

Очевидно, что даже при визуальной оценке резкость, контраст и соответственно количество обнаруживаемых деталей строения семени на снимке с прямым рентгеновским увеличением существенно больше, чем на оптически увеличенном контактном снимке.

Для реализации метода микрофокусной съемки семян специалистами Агрофизического научно-исследовательского института и Санкт-Петербургского государственного электротехнического университета „ЛЭТИ“ им. В.И. Ульянова (Ленина) разработан совместно аппаратно-программный комплекс на основе передвижной рентгенодиагностической установки ПРДУ-02 для контроля качества семян и зерна [21]. В состав установки ПРДУ-02 (рис. 7) входят: рентгенозащитная камера для проведения рентгенографических работ; источник рентгеновского излучения моноблочного типа РАП70М-0.1Н-1; приемник рентгеновского изображения на основе экрана с фотостимулируемым люминофором, либо многофункционального портативного плоскопанельного детектора для цифровой рентгенографии; 
$a$
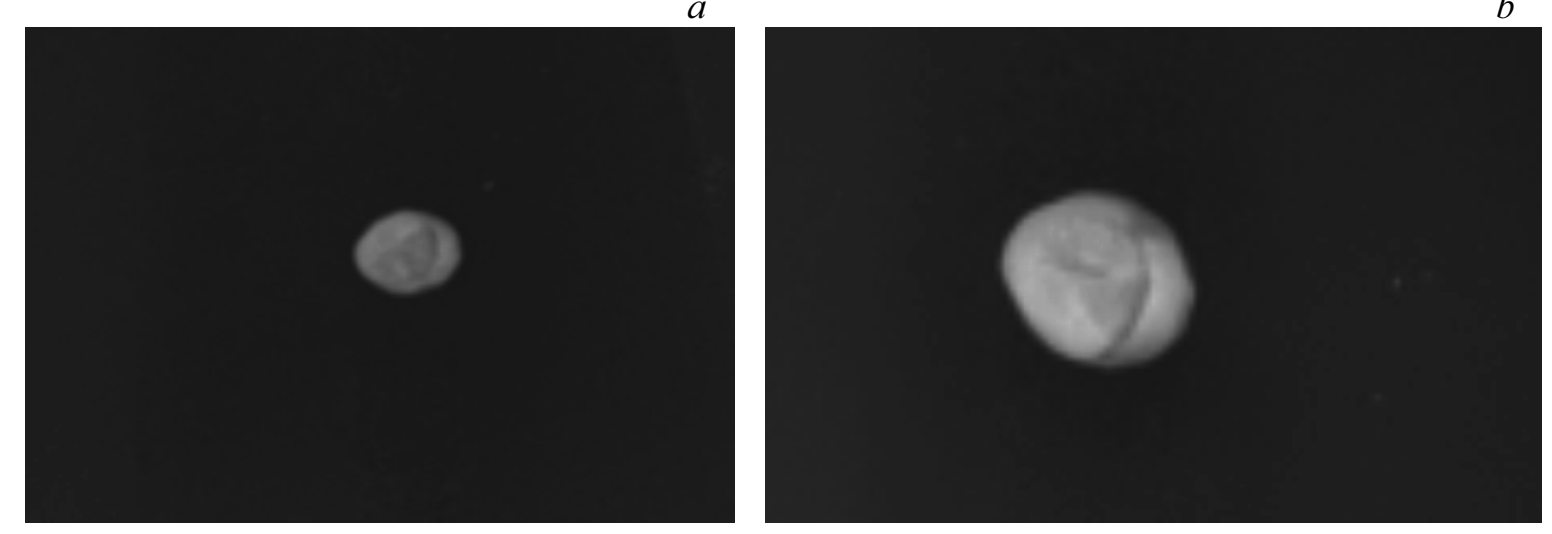

$c$
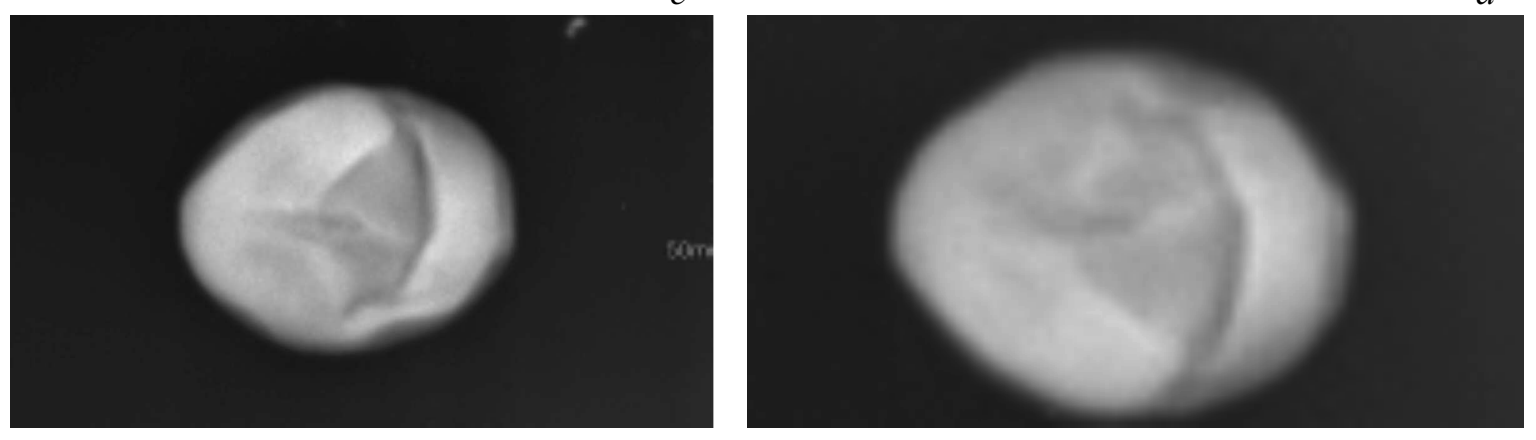

Рис. 4. Рентгеновские снимки тест-объекта (семя гороха), полученные на аппарате с протяженным фокусным пятном: $a-$ без увеличения изображения; $b-d-$ с коэффициентом увеличения изображения $m$, равным 2, 4, 8 соответственно [19].

$a$
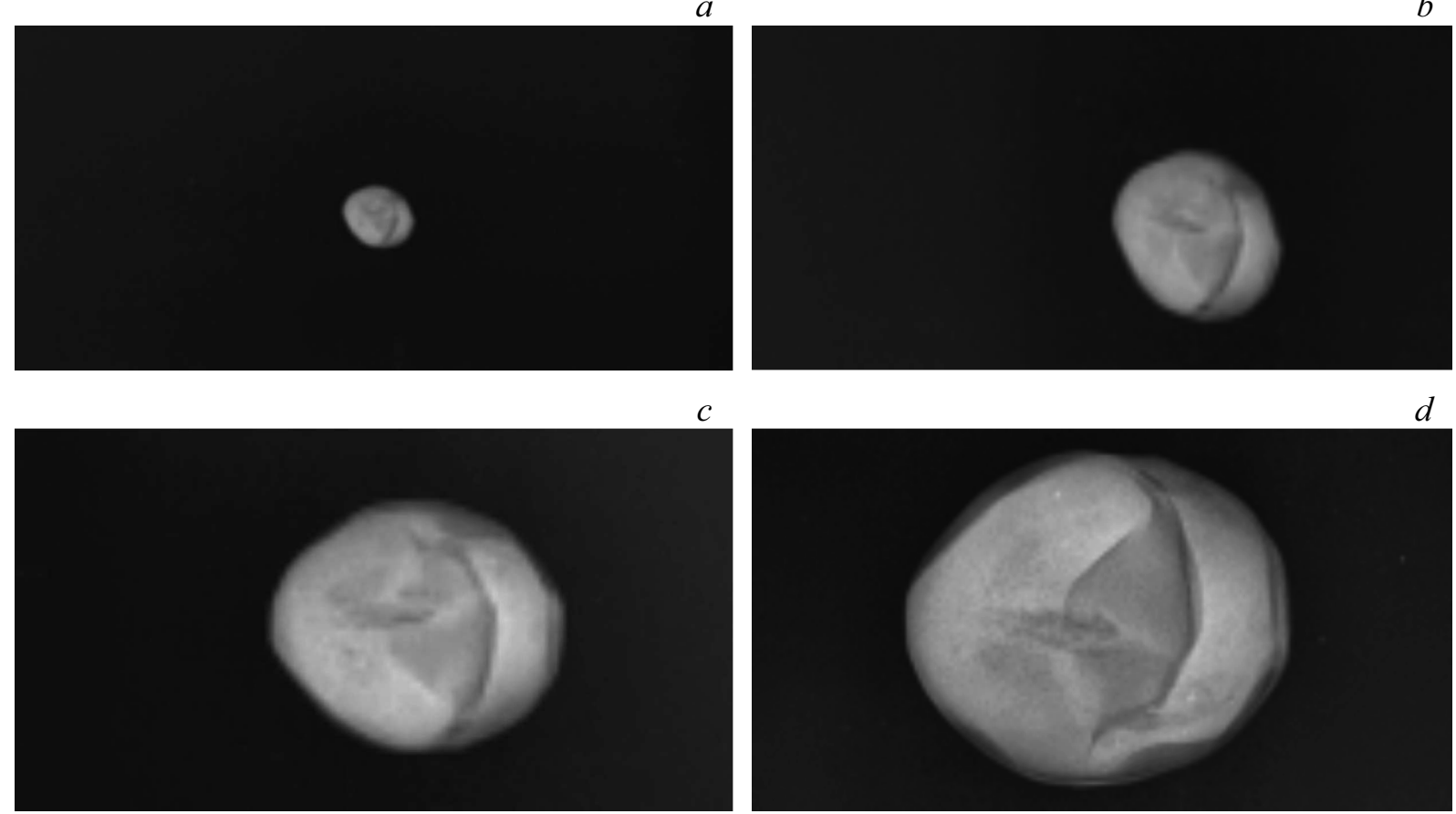

$c$

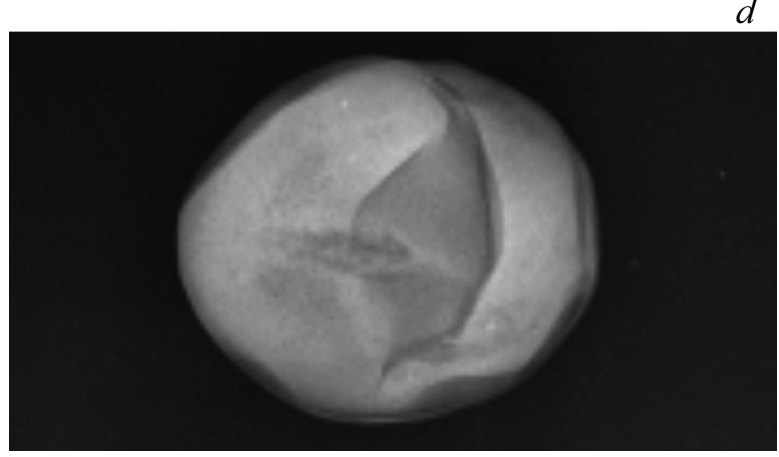

Рис. 5. Рентгеновские снимки тест-объекта, полученные на аппарате с точечным фокусным пятном: $a$ - без увеличения изображения; $b-d-$ с коэффициентом увеличения изображения $m$, равным $2,4,8$ соответственно. 
$a$

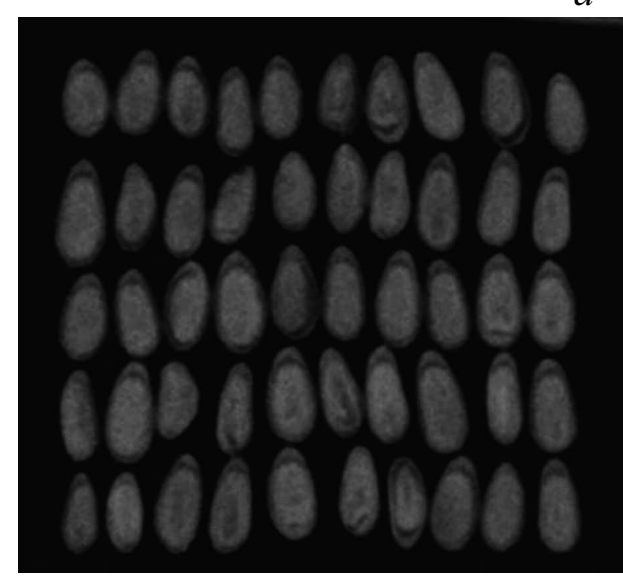

$b$

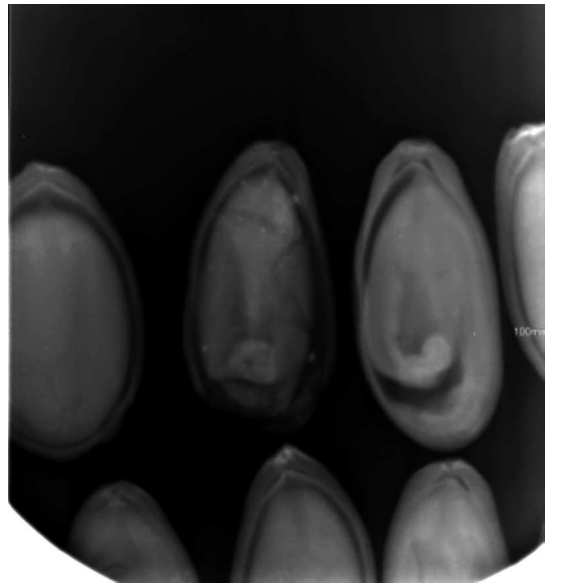

$c$

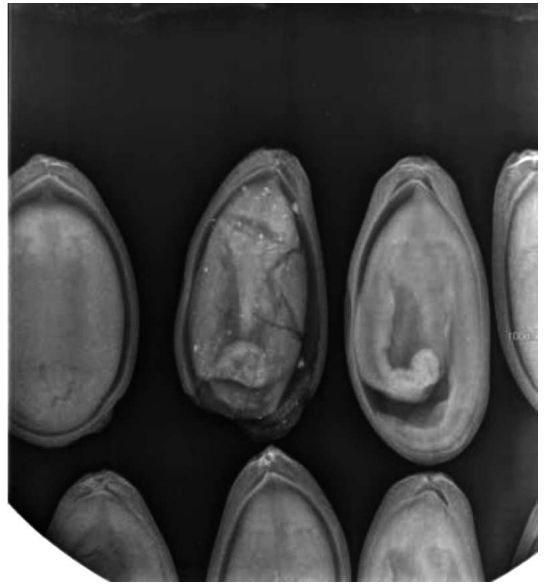

Pис. 6. Рентгенограммы семян артишока, полученные: $a-$ при контактной съемке; $b-$ фрагмент контактной рентгенограммы с последующим оптическим увеличением; $c$ - тот же фрагмент карточки при прямом рентгеновском увеличении.

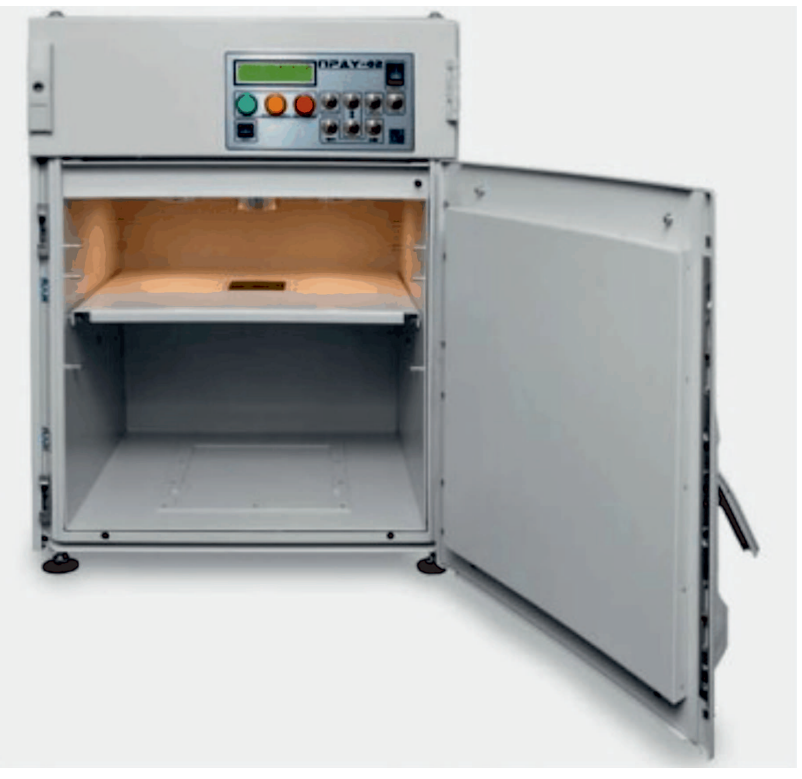

Рис. 7. Рентгенодиагностическая установка ПРДУ-02.

управляющая рабочая станция с универсальным [22], либо специализированным [23] программным обеспечением для анализа цифровых рентгеновских изображений семян.

Установка ПРДУ-02 позволяет получать одновременно изображения от нескольких единиц до нескольких сотен семян с увеличением до десяти крат. Этого достаточно, чтобы выявить основные типы дефектов семян: невыполненность, дефекты зародыша, травмированность, скрытую заселенность и поврежденность насекомыми, скрытое прорастание семян и др.

Использование микрофокусного источника рентгеновского излучения позволяет получать проекционные изображения с повышенным пространственным разрешением за счет использования прямого геометрического увеличения в процессе съемки. Эта отличительная особенность микрофокусных рентгеновских аппаратов, кроме классической рентгенографии, также может быть использована при получении томографических изображений, что дает начало развитию отдельной области техники - микрофокусной рентгеновской компьютерной томографии или микротомографии [24].

С целью отработки методик применения микрофокусной рентгеновской компьютерной томографии и экспериментальной проверки требований по точности юстировки элементов томографической системы сотрудниками кафедры электронных приборов и устройств Санкт-Петербургского государственного электротехнического университета „ЛЭТИ“ разработан макет микрофокусного рентгеновского компьютерного томографа семейства МРКТ (рис. 8) [25].

В качестве источника излучения в МРКТ-01 использован моноблочный рентгеновский аппарат РАП150М01Н-5 (ЗАО „ЭЛТЕХ-Мед“, Санкт-Петербург) на основе отпаянной микрофокусной рентгеновской трубки БС-16 (АО „Светлана-Рентген“, Санкт-Петербург). Основные технические характеристики томографа МРКТ-01 представлены в табл. 1.

Малые размеры фокусного пятна, достигаемые за счет использования двойной системы фокусировки электронного пучка, позволяют получать рентгеновские изображения с геометрическим увеличением до 200 раз. Эффективный размер вокселя томографических изображений, полученных в таких условиях, достигает $1 \mu \mathrm{m}[25]$. 
$a$

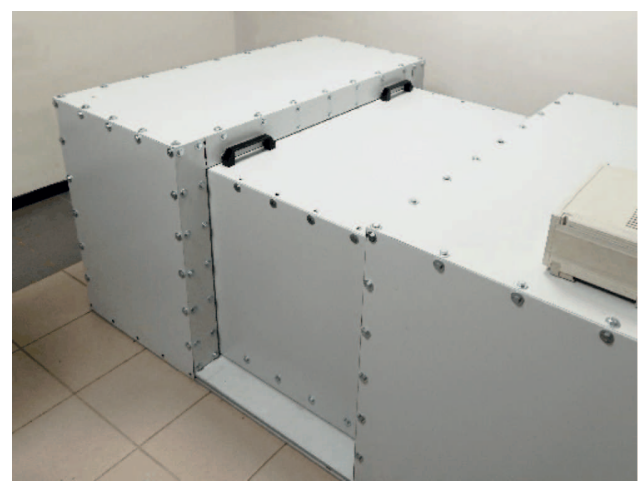

$b$

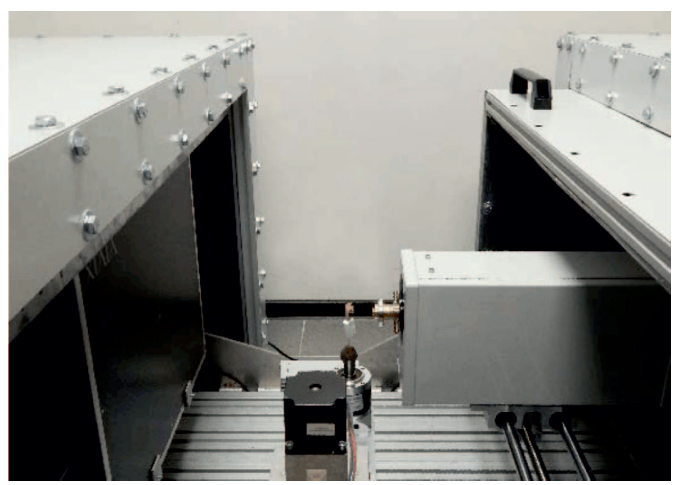

Рис. 8. Микрофокусный рентгеновский компьютерный томограф МРКТ-01: $a-$ внешний вид; $b-$ источник и приемник излучения с системой перемещения объекта.

Таблица 1. Основные технические характеристики томографа МРКТ-01

\begin{tabular}{l|c}
\hline Анодное напряжение, $\mathrm{kV}$ & $40-150$ \\
\hline Анодный ток, $\mathrm{mA}$ & $0.01-0.2$ \\
\hline Размер фокусного пятна, $\mu \mathrm{m}$ & 1 \\
\hline Разрешающая способность, $\mu \mathrm{m}$ & 30 \\
\hline $\begin{array}{l}\text { Эквивалентная толщина объекта томографии (по алюминию), } \mathrm{mm} \\
\text { не менее }\end{array}$ & $300 \times 150 \times 150$ \\
\hline Габариты объекта томографии, $\mathrm{mm}$ не более & 500 \\
\hline Потребляемая мощность, $\mathrm{W}$ & $1800 \times 1200 \times 800,500$
\end{tabular}

\section{2. Основные способы визуализации и анализа цифровых рентгеновских и компьютерных микротомографических изображений семян}

На рис. 9 представлены примеры „сырых“ необработанных цифровых рентгеновских изображений семян пшеницы, полученных с использованием передвижной рентгенодиагностической установки ПРДУ-02.

Автоматическая обработка цифровых рентгеновских изображений, реализованная с помощью программного обеспечения для анализа изображений „ARGUS-BIO“ (ООО „АргусСофт“, Санкт-Петербург), основана на:

- базовом анализе цифровых рентгеновских изображений, позволяющем количественно оценить размерные (площадь проекции, длина, ширина и др.), геометрические (фактор круга, фактор эллипса, округлость и др.) и яркостные (средняя яркость, среднеквадратическое отклонение яркости, оптическая плотность) [26] характеристики рентгенограмм семян. Наиболее успешно данный принцип реализован при анализе цифровых рентгеновских изображений семян, имеющих дефект „невыполненность,, часто встречающийся, в частности, у семян древесных лесных пород (рис. 10).

На рис. 11. представлен пример анализа цифровых рентгеновских изображений кедрового стланика. Последовательность анализа изображений включает в себя выделение области интереса (рис. 11, $a$ ), автоматическое выделение объектов интереса по порогу яркости (рис. $11, b$ ), автоматическое измерение выделенных объектов интереса, их классификация (рис. $11, c$ ). В данном случае объекты классифицированы на два класса $(1-$ „Empty“ и 2 - „Normal“). Классификация осуществлена по параметру „Средняя яркость“.

Численные значения показателя „Средняя яркость“ по каждому измеренному объекту приведены в табл. 2.

- дифференцированном анализе цифровых рентгеновских изображений, позволяющем количественно оценить основные геометрические и денситометрические характеристики не только семени в целом, но и его отдельных структур и органов. Данный принцип реализован при анализе цифровых рентгеновских изображений крупных семян древесных лесных пород (семейства кедровые), имеющих достаточную контрастность 

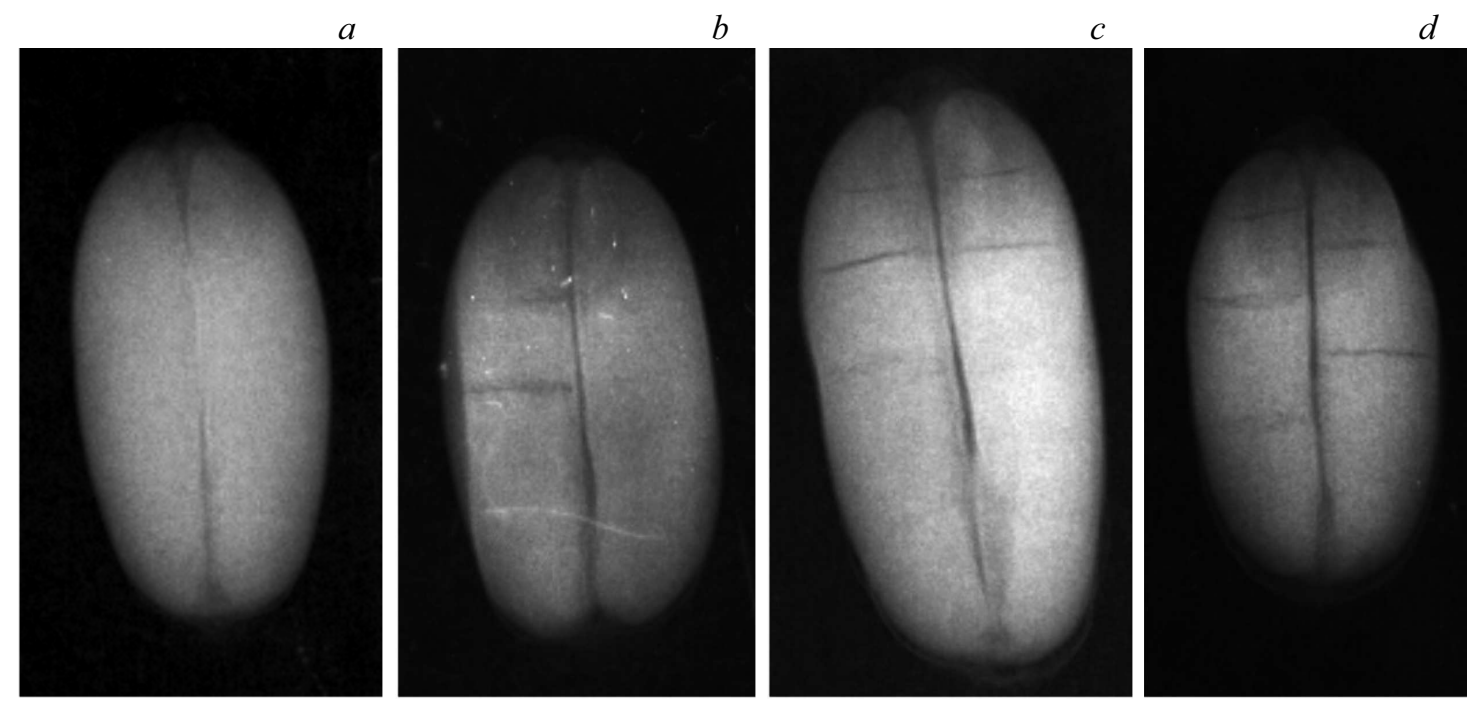

Рис. 9. Цифровые рентгеновские изображения семян пшеницы (3-х кратное рентгеновское увеличение): $a-$ семя без дефектов, $b-$ семя со скрытым дефектом биогенного происхождения -1 (пораженность эндосперма грибной инфекцией), $c-$ семя со скрытым дефектом биогенного происхождения - 2 (пораженность зародыша грибной инфекцией), $d-$ семя со скрытым дефектом техногенного происхождения (трещиноватость эндосперма).

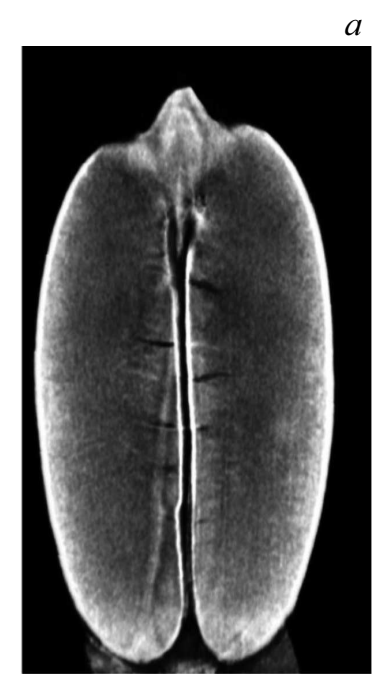

$a$
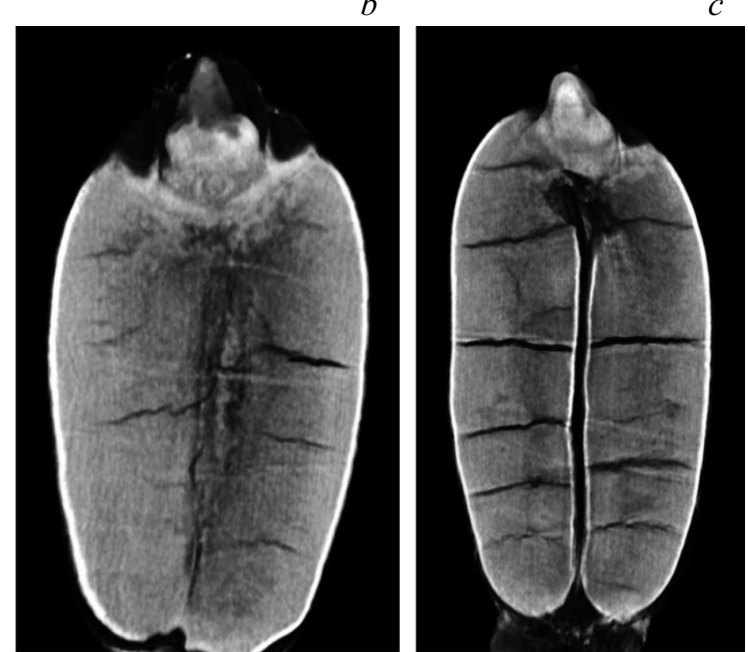

$c$
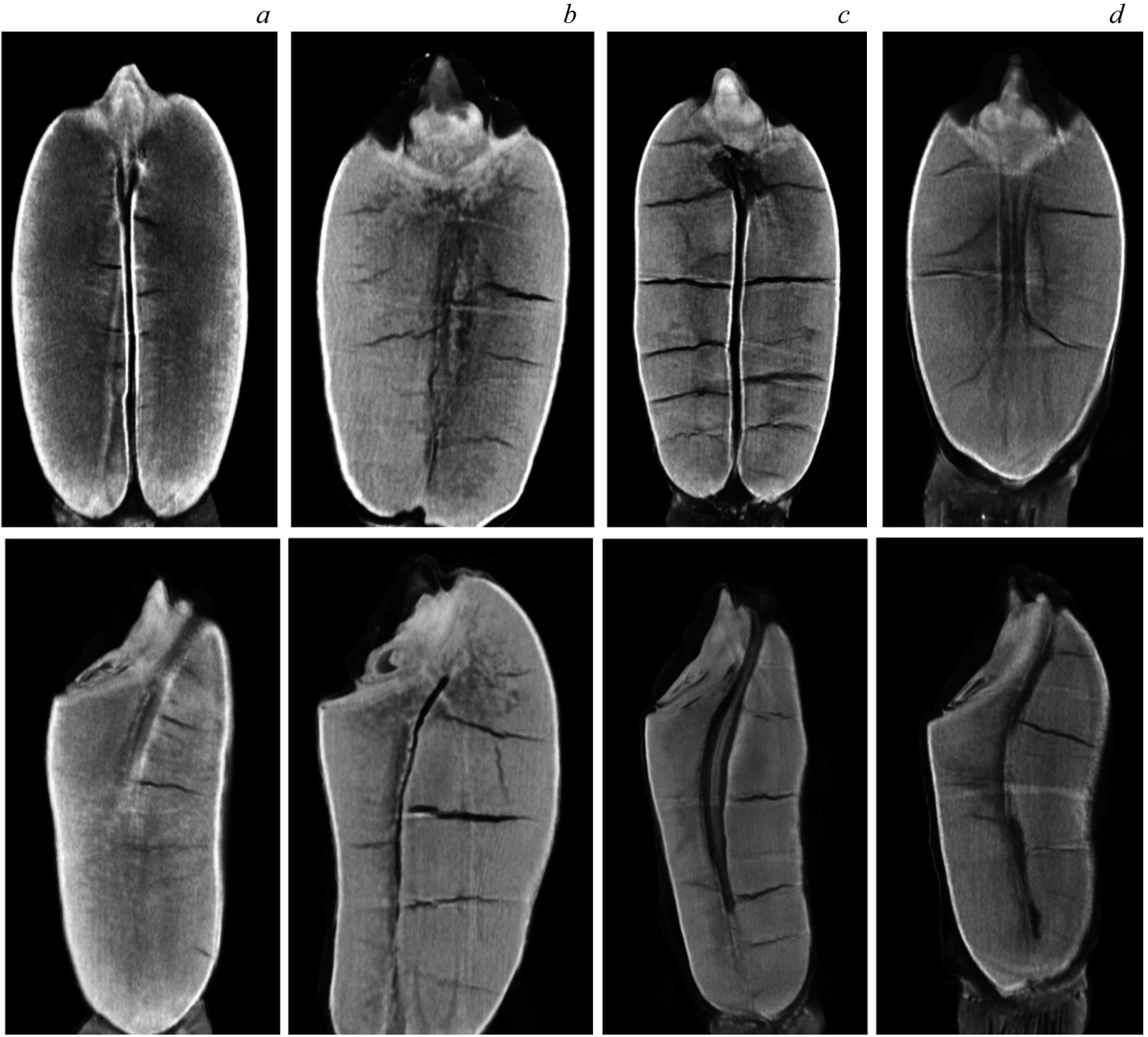

Рис. 10. Томографические изображения семян пшеницы. Фронтальные виртуальные сечения (верхний ряд), сагиттальные виртуальные сечения (нижний ряд): $a-$ семя без дефектов, $b-$ семя со скрытым дефектом биогенного происхождения - 1 (пораженность эндосперма грибной инфекцией); $c$ - семя со скрытым дефектом биогенного происхождения - 2 (пораженность зародыша грибной инфекцией); $d$ - семя со скрытым дефектом техногенного происхождения (трещиноватость эндосперма). 


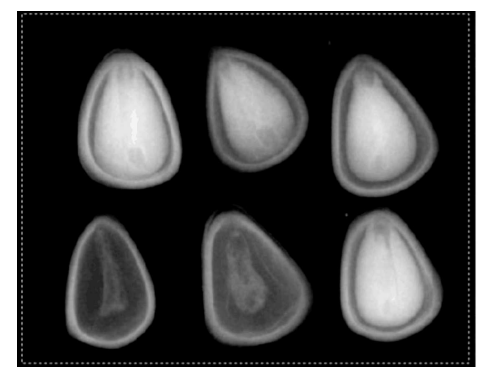

$b$

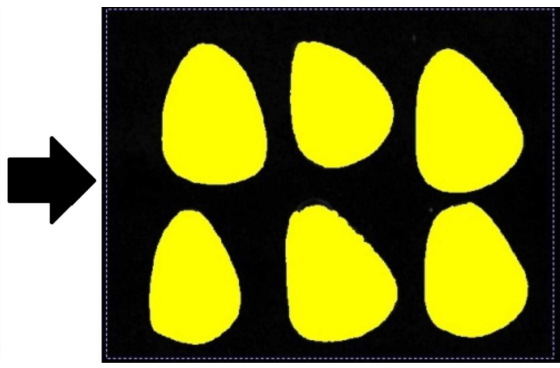

C

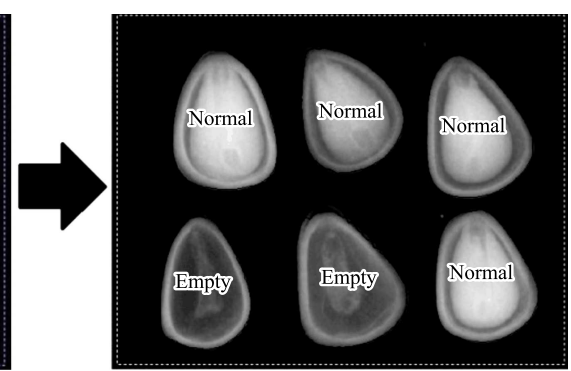

Рис. 11. Основные этапы компьютерной обработки цифровых рентгеновских изображений на примере семян кедрового стланика, выполненные в программном обеспечении „ARGUS-BIO“.

Таблица 2. Денситометрические характеристики семян кедрового стланика, полученные путем интегрального анализа цифровых рентгеновских изображений

\begin{tabular}{|c|c|c|c|c|c|c|}
\hline \multirow{2}{*}{$\begin{array}{c}\text { Показатель, единицы } \\
\text { измерения }\end{array}$} & \multicolumn{6}{|c|}{ № семени } \\
\hline & 1 & 2 & 3 & 4 & 5 & 6 \\
\hline $\begin{array}{l}\text { Средняя яркость, } \\
\text { единицы яркости } \\
\text { Класс объекта }\end{array}$ & $\begin{array}{l}133.91 \\
\text { Normal }\end{array}$ & $\begin{array}{l}102.27 \\
\text { Normal }\end{array}$ & $\begin{array}{l}109.88 \\
\text { Normal }\end{array}$ & $\begin{array}{l}67.88 \\
\text { Empty }\end{array}$ & $\begin{array}{l}75.16 \\
\text { Empty }\end{array}$ & $\begin{array}{r}126.84 \\
\text { Normal }\end{array}$ \\
\hline
\end{tabular}
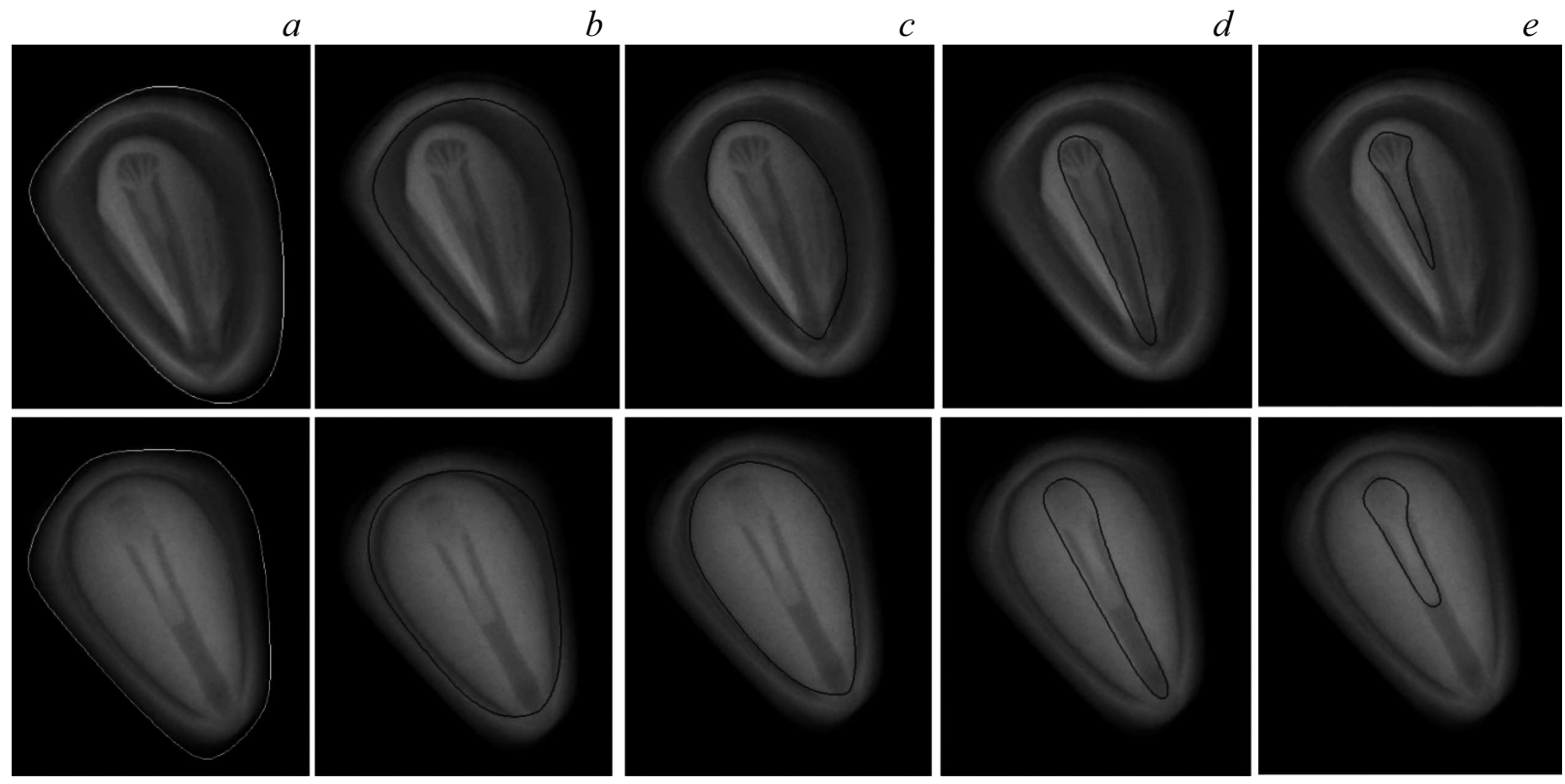

Рис. 12. Пример программной обработки цифровых рентгеновских изображений семян сосны кедровой, выполняемой путем интерактивного нанесения нескольких контуров, соответствующих отдельным структурам и органам семени: $a-$ внешний контур, соответствующий наружной оболочке (кожуре); $b$ - внутренний контур кожуры; $c$ - контур, соответствующий области эндосперма; $d-$ контур, соответствующий области ложа; $e-$ контур, соответствующий области зародыша. Верхний ряд - семя, имеющее дефектный зародыш и эндосперм; нижний ряд - семя без дефектов.

для интерактивного программного выделения контуров, соответствующих различных структурам и органам семени.

На рис. 12 представлен пример дифференцированного анализа цифровых рентгеновских изображений семян сосны кедровой: семя № 1, имеющее скрытые дефекты внутренней структуры, и семя № 2 - без скрытых дефектов. По нанесенным контурам в программе автоматически производятся геометрические и денситометрические измерения. 
Таблица 3. Количественные характеристики отдельных структур и органов семян, полученные путем дифференцированного анализа цифровых рентгеновских изображений

\begin{tabular}{|c|c|c|c|}
\hline \multirow{2}{*}{$\begin{array}{l}\text { № } \\
\Pi / \Pi\end{array}$} & \multirow{2}{*}{ Показатель, единицы измерения } & \multicolumn{2}{|c|}{ Значения показателей } \\
\hline & & Семя № 1 & Семя № 2 \\
\hline 1 & Площадь проекции зародыша, $\mathrm{mm}^{2}$ & 10.61 & 13.07 \\
\hline 2 & Средняя яркость проекции зародыша, единицы яркости & 118.46 & 143.13 \\
\hline 3 & Отношение площадей проекции зародыша и проекции ложа, \% & 42.66 & 48.52 \\
\hline 4 & Относительная площадь проекции зародыша, \% & 5.32 & 7.00 \\
\hline 5 & Фактор эллипса области проекции зародыша, относительные единицы & 0.86 & 0.929 \\
\hline 6 & Площадь проекции эндосперма, $\mathrm{mm}^{2}$ & 44.31 & 65.20 \\
\hline 7 & Относительная площадь области эндосперма, \% & 34.67 & 49.37 \\
\hline 8 & Относительная площадь области отслоения оболочки, \% & 28.27 & 15.62 \\
\hline
\end{tabular}
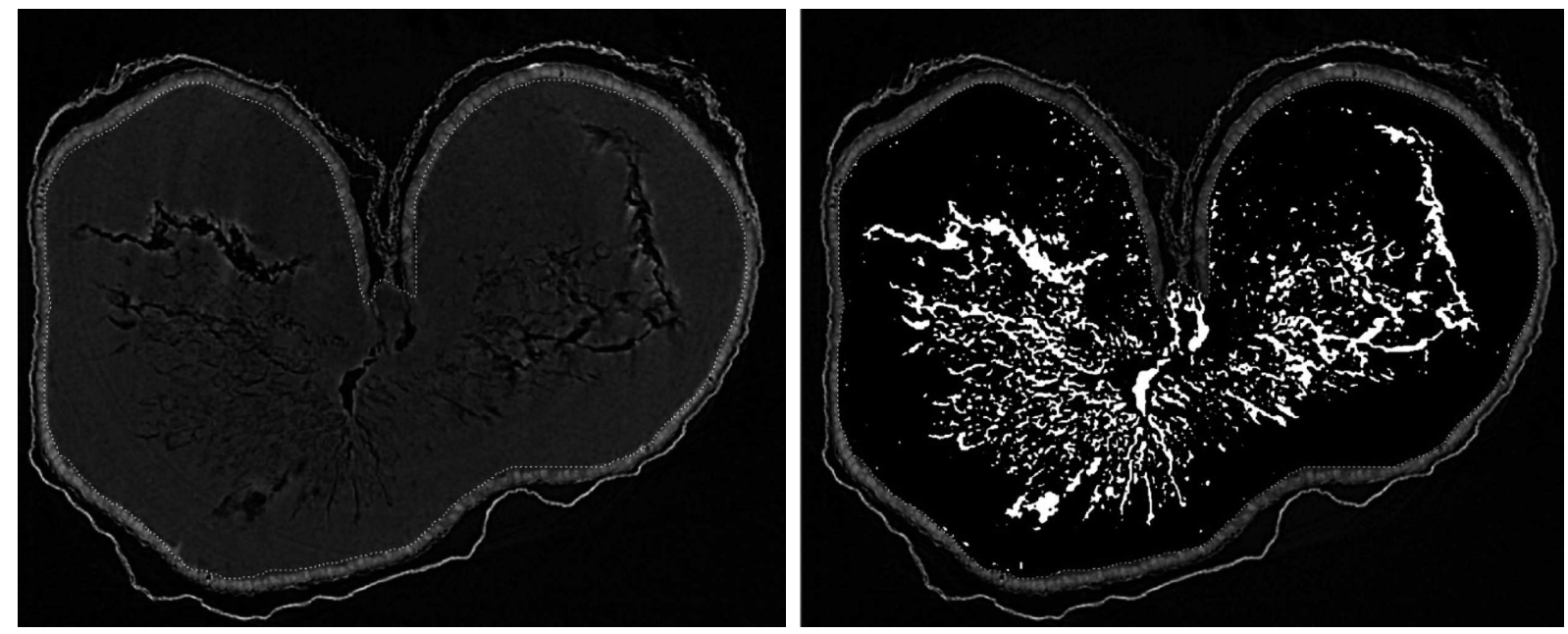

Рис. 13. Пороговое выделение неповрежденной и поврежденной областей семени пшеницы.

Основные характеристики, полученные по результатам дифференцированных измерений цифровых рентгеновских изображений семян, приведены в табл. 3.

Количественный анализ компьютерных микротомографических изображений применим, в частности, с позиции оценки объемной доли выявленного дефекта и может быть выполнен с использованием программного обеспечения CTAn. Основные этапы обработки микротомографических изображений семян включают в себя: предварительную фильтрацию исходных изображений (сглаживание шумов) и пороговое выделение неповрежденной и поврежденной областей семени (рис. 13). Далее диапазоны пороговых значений экстраполируются на весь массив исходных микротомографических изображений (> 1000 шт.). На основании анализа массива исходных изображений осуществляется автоматический расчет объемной доли поврежденной области семени, \%.

По данным измерений в программе CTAn объемная доля пораженной ткани (общая пористость) семени составила $8.55 \%$.

\section{3. Оценка энергии прорастания, всхожести и компьютерная морфометрия проростков как интегральных показателей для оценки биологической полноценности семян}

Комплексная методика оценки качества семенного материала включает в себя морфометрические измерения семян, состоящие из следующих этапов [27]: определение энергии прорастания, всхожести [28]; измерение длины и/или массы ростков и корней; ранжирование ростовых показателей по классам. Для морфометрических измерений семян наиболее удобен способ проращивания в рулонах. Преимуществами оценки посевных качеств семян (рулонный способ проращивания) в сочетании с компьютерной морфометрией проростков являются:

- простота соблюдения нумерации семян в опыте, необходимой для сопоставления рентгеновских и ростовых показателей; 


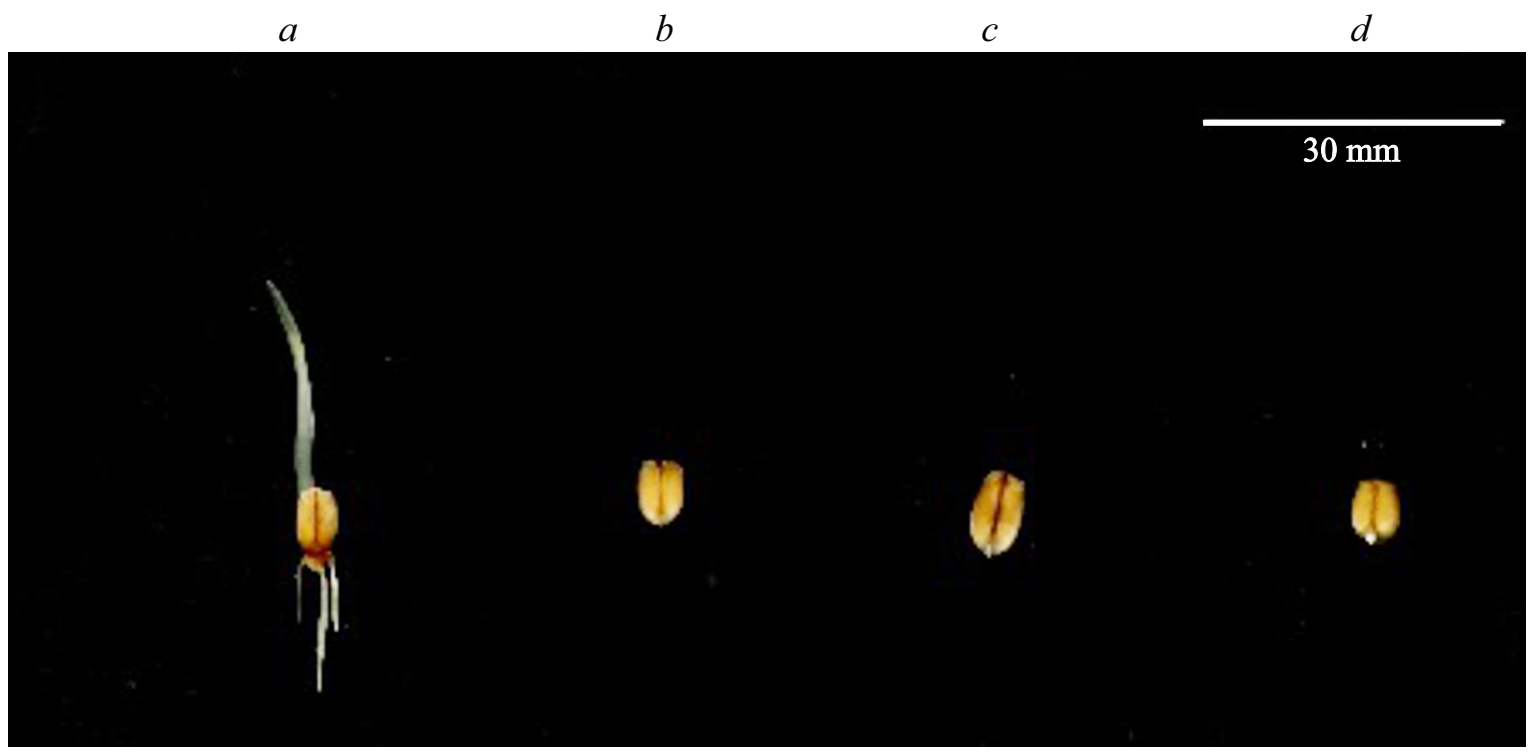

Рис. 14. Цифровые рентгеновские изображения семян пшеницы после проведенного теста на проращивание.

Таблица 4. Сравнительная оценка возможностей методов цифровой микрофокусной рентгенографии и компьютерной микротомографии для исследований качества семян

\begin{tabular}{|c|c|c|c|}
\hline № ா/ா & Показатель & $\begin{array}{l}\text { Микрофокусная } \\
\text { рентгенография }\end{array}$ & $\begin{array}{c}\text { Компьютерная } \\
\text { микротомография }\end{array}$ \\
\hline 1. & \multicolumn{3}{|c|}{ Информативность метода } \\
\hline 1.1. & $\begin{array}{l}\text { Гарантированная визуализация } \\
\text { скрытых дефектов семени всех видов растений }\end{array}$ & & \\
\hline 1.2 & $\begin{array}{l}\text { Возможность количественной оценки } \\
\text { изображений }\end{array}$ & + & + \\
\hline 1.3. & $\begin{array}{l}\text { Возможность получения характеристик } \\
\text { дефектности индивидуального семени }\end{array}$ & + & + \\
\hline 2. & \multicolumn{3}{|c|}{ Ресурсоемкость } \\
\hline $\begin{array}{l}2.1 . \\
2.2 . \\
2.3 .\end{array}$ & $\begin{array}{l}\text { Скорость получения изображения одного } \\
\text { образца } \\
\text { Требования к ресурсам ПК } \\
\text { Экономичность методики } \\
\end{array}$ & $\begin{array}{c}<2 \text { min } \\
100 \text { шт. семян } \\
\text { Средние } \\
\text { Средняя } \\
\end{array}$ & $\begin{array}{c}\sim 60 \text { min } \\
\text { одно семя } \\
\text { Высокие } \\
\text { Низкая } \\
\end{array}$ \\
\hline 3. & $\begin{array}{l}\text { Сохранение жизнеспособности объекта } \\
\text { исследований }\end{array}$ & + & + \\
\hline
\end{tabular}

Примечани е: * зависит от вида растения и способа его укладки при рентгеновской съемке.

- высокая точность измерений, в том числе - длины изогнутых объектов (зародышевых побегов и корней);

- возможность быстрого документирования большого количества исходных экспериментальных данных (сканированных изображений) с последующим анализом в удобное для исследователя время.

Измерение ростовых показателей (длина зародышевого побега и корня) осуществляются в программном обеспечении „ARGUS-BIO“. Полученные данные сопоставляются с оценкой внутренней дефектности семян, выполненные с использованием метода рентгенографии [27].
Цифровые сканированные изображения семян пшеницы после проведенного теста на проращивание представлены на рис. 14. Полученные данные свидетельствуют, что скрытые дефекты семян, отмеченные на рис. 9 и 10 $(b, c$ и $d)$, привели к потере их жизнеспособности и утрате посевных качеств. Морфометрические измерения семени пшеницы без дефектов (рис. 14,a) показали следующие результаты: энергия прорастания „+““, всхожесть „+“, длина зародышевого побега - $21.20 \mathrm{~mm}$, количество зародышевых корней - 3 шт., длина максимального зародышевого корня - $13.11 \mathrm{~mm}$. 


\section{Заключение}

Сравнительная оценка возможностей методов цифровой микрофокусной рентгенографии и компьютерной микротомографии для изучения особенностей внутренних структуры семени, связанных с нарушением его целостности, представлена в табл. 4.

С учетом преимуществ метода микрофокусной рентгенографии (высокая скорость получения изображений, сравнительная экономичность), а также определенных ограничений по информативности метода при исследованиях семян некоторых видов растений [13], можно рекомендовать метод, прежде всего, для решения прикладных (рутинных задач) исследований качества семенного материала:

- первичный скрининг, выявление и идентификация скрытых дефектов семян различных категорий, определение доли этих дефектов в исследуемых партиях семенного материала для оценки их потенциальной всхожести [29];

- обнаружение зараженности семян вредителями в скрытой форме, в том числе, относящихся к объектам карантинного контроля [30];

- коррекция применяемых агротехнологий и культуры производства на основе рентгенографического анализа с целью сведения внутренней дефектности семян до минимального уровня [27].

При условии получения нескольких проекций рентгеновских изображений для одних и тех же семян информативность метода микрофокусной рентгенографии может быть повышена [31].

Высокая информативность метода компьютерной микротомографии с учетом факторов, лимитирующих ее широкое применение в семеноведении (временные затраты на проведение исследований и стоимость оборудования), позволяет рекомендовать данный метод для решения фундаментальных задач семеноведения в том числе контроля результатов селекционного процесca [32]. При этом необходимо принимать во внимание и более углубленно исследовать возможное влияние рентгеновского излучения как на сами семена, так и на присутствующую на них микрофлору [33,34].

Авторы выражают признательность сотруднику Ресурсного центра „Рентгенодифракционные методы исследования“ Санкт-Петербургского государственного университета А.М. Кулькову за проведенный компьютерный анализ микротомографического изображения семени пшеницы.

\section{Список литературы}

[1] Батыгин Н.Ф. Онтогенез высших растений. Всесоюз. Акад. с.-х. наук им. В.И. Ленина. М.: Агропромиздат, 1986. $100 \mathrm{c}$.

[2] ОСТ 56-94-88. Семена древесных пород. Методы рентгенографического анализа. М., 1988.
[3] Международный стандарт ИСО 1162-75 „Зерно и зернобобовые. Определение зараженности и поврежденности вредителями методом рентгенографии“". 1980. 5 с.

[4] ГОСТ 28666.4-90 (ИСО 6639/4-87) Зерновые и бобовые. Определение скрытой зараженности насекомыми. Ч. 4. Ускоренные методы.

[5] Методика анализа семян. М., 1995. 399 с.

[6] Архипов М.В., Потрахов Н.Н. Микрофокусная рентгенография растений. СПб.: Технолит, 2008. 192 с.

[7] Narvankara D.S., Singha C.B., Jayasa D.S., White N.D.G. // Biosystems Engineering. 2009. Vol. 103. P. 49-56.

[8] Pinto T.L.F., Cicero S.M., França-Neto J.B., Forti V.A. // Seed Sci. Technol. 2009. Vol. 37. N 1. P. 110-120.

[9] Gomes-Junior F.G., Yagushi J.T., Belini U.L., Cicero S.M. // Seed Sci. Technol. 2012. Vol. 40. N 1. P. 102-107.

[10] Silva V.N., Cicero S.M., Bennett M. // Seed Sci. Technol. 2013. Vol. 41. N 2. P. 225-234.

[11] Rousseau D., Widiez T., Di Tommaso S., Rositi H., Adrien J., Langer M.E., Olivier C., Peyrin F., Rogowsky P. // Plant Methods. 2015. 11:55. P. 1-10. DOI: $10.1186 / \mathrm{s} 13007-015-0098-\mathrm{y}$

[12] Cloetens P., Mache R., Schlenker M., Lerbs-Mache S. // Proc. National Academy of Science of the United States of America. 2006. Vol. 103. N 39. P. 14626-14630. DOI: $10.1073 /$ pnas.0603490103

[13] Gomes-Junior F.G., van Dujin B. // Seed Testing International. 2017. N 154. P. 48-52.

[14] Trigui G., Boudehri-Giresse K., Le Corre L. How does Microtomography provide access to full seed morphology? Current applications and future prospects / 31th ISTA Congress - Seed Symposium. Tallinn, Estonia, 15-17 June, 2016. P. 66.

[15] Ham H., du Plessis A., le Roux S.G. // New Zealand J. Forestry Sci. 2017. Vol. 47. P. 1-8. doi.org/10.1186/s40490-016-0084-9

[16] Блинов Н.Н., Леонов Б.И. Рентгеновские диагностические аппараты: в 2 т. М.: ВНИИИМТ, НПО „Экран“, 2001. Т. 2. $140 \mathrm{c}$.

[17] Мазуров А.И., Потрахов Н.Н. // Медицинская техника. 2011. № 5. С. 30-34.

[18] Васильев А.Ю. Рентгенография с прямым многократным увеличением в клинической практике. М.: ИПТК „Логос“ BOC, 1998. $148 \mathrm{c}$.

[19] Мусаев Ф.Б., Потрахов Н.Н., Архипов М.В. Рентгенография семян овощных культур. СПб.: ЛЭТИ, 2016. 206 с.

[20] Потрахов Н.Н. // Вестн. новых мед. технологий. 2007. T. XIV. № 3. C. 167-169.

[21] Пат. РФ № 85292, МПК А01С 1/02. Устройство для рентгенодиагностических исследований зерна и семян / Архипов М.В., Демьянчук А.М., Великанов Л.П., Потрахов Н.Н., Грязнов А.Ю., Потрахов Е.Н. Заявлено 13.04.2009; зарег. 10.08.2009; опубл. 10.08.2009. Бюл. № 22.

[22] Прияткин Н.С., Колесников Л.Е., Архипов М.В., Гусакова Л.П., Кузнеи, С.М. Перспективы использования методик автоматизированного анализа изображений в лесном семеноводстве и лесной фитопатологии. / Тезисы V Междунар. науч.-практ. конф. „Инновации и технологии в лесном хозяйстве“ ITF-2016, СПб, ФБУ „СПбНИИЛХ“ 31 мая-2 июля 2016 г. СПб.: СПбНИИЛХ, 2016. С. 116.

[23] Желудков А.Г., Белеикий С.Л., Потрахов Н.Н. // Хлебопродукты. 2016. № 5. С. 58-61.

[24] Бессонов В.Б., Ободовский А.В., Клонов В.В., Кострин Д.К. // Евразийский союз ученых. 2014. № 5-3 (5). C. $12-15$. 
[25] Ободовский А.В., Бессонов В.Б., Ларионов И.А. Смещение фокусного пятна рентгеновской трубки с прострельным анодом при длительных экспозициях / Материалы IV Всероссийской научно-практической конференции производителей рентгеновской техники. СПб.: Изд-во СПбГЭТУ „ЛЭТИ“, 2017. С. 68-71.

[26] Архипов М.В., Прияткин Н.С., Колесников Л.Е. // Известия Санкт-Петербургского гос. аграрного ун-та. 2016. № 44. C. 21-27.

[27] Архипов М.В., Гусакова Л.П., Великанов Л.П., Виличко А.К., Желудков А.Г., Алферов В.Б. Методика комплексной оценки биологической и хозяйственной пригодности семенного материала. Методические рекомендации. СПб.: АФИ, 2013. $52 \mathrm{c}$.

[28] ГОСТ 12038-84. Семена сельскохозяйственных культур. Методы определения всхожести.

[29] Архипов М.В., Прияткин Н.С., Потрахов Н.Н., Гусакова Л.П., Журавлева Е.В. Системный подход к оценке разнокачественности семян зерновых культур на основе использования современных методов интроскопической диагностики // Труды Кубанского гос. аграрного ун-та. 2015. Вып. 3. № 54. С. 79-83.

[30] Архипов М.В., Алексеева Д.И., Великанов Л.П., Гусакова Л.П. Интроскопический метод ускоренного определения скрытой заселенности зерна карантинными вредителями: методические рекомендации // СПб.: Агрофизический НИИ РАСХН, 2005. 24 с.

[31] Grundas S., Velikanov L., Archipov M. // Int. Agrophysics. 1999. Vol. 13. P. 355-361.

[32] Прияткин Н.С., Архипов М.В., Гусакова Л.П. Возможности и перспективы методов исследования скрытой неоднородности семян и их реализация в селекции, семеноводстве и защите растений. / В сборнике: Тенденции развития агрофизики: от актуальных проблем земледелия и растениеводства к технологиям будущего Материалы Международной научной конференции, посвященной 85летию Агрофизического НИИ. 2017. С. 810-814.

[33] Zappala S., Helliwell J.R., Tracy S.R., Mairhofer S., Sturrock C.J., Pridmore T., Bennett M., Mooney S.J. // PLOS ONE. 2013. Vol. 8. N 6. P. 1-8.

doi.org/10.1371/journal.pone.0067250

[34] Ikram N., Dawar S., Imtiaz F. // J. Plant Pathology \& Microbiology. 2015. S3:003.

https: doi:10.4172/2157-7471.S3-003 